\title{
La fortificación hispanomusulmana de la madīna de Burriana (Castellón)
}

The Spanish-Muslim fortification of the Burriana's medina (Castellón)

\section{José Manuel Melchor Monserrat}

Museo Arqueológico Municipal, Burriana, Spain, arqueologo@burriana.es

\begin{abstract}
This communication aims to publicize the latest archeological findings related to the Spanish-Muslim wall of Burriana, obtained thanks to the interventions carried out throughout the twenty-first century, in which new sectors and towers of the wall have been evidenced, and that they also clarify some ancient historical and archaeological news about the fortification. We highlight the documentation of the construction technique of the wall, which provides interesting data on its chronology, recently established around the eleventh century. The relationship between the defensive structure and other recent archaeological findings associated with this period are examined, such as some necropolis and elements of the urban plot. Finally, an analysis of the historical and territorial context of the defensive structure and the Spanish-Muslim city will be carried out, since Burriana's medina was an important administrative and commercial center, a stopping point on the land route between Tortosa and Valencia, and cited as an amal that also had a seaport, according to some sources.

We do not forget that the madina is also a prominent enclave in the historical events related to the Christian razzias of the eleventh and twelfth centuries, and in the subsequent process of conquest of the kingdom of Valencia at the beginning of the thirteenth century, as reflected in the chronicles of the time.
\end{abstract}

Keywords: Archeology, medieval, wall, architecture.

\section{Introducción}

El emplazamiento de la ciudad de Burriana (Fig. 1) es fruto de una serie de factores geográficos y sociales que marcaron su evolución histórica. En primer lugar, está ubicada en una zona llana rodeada de montañas, con terreno fértil, profusión de caza y pesca, y una costa con marjales que dificultaban el asentamiento humano. En segundo término, los agentes antrópicos fueron igualmente decisivos, como por ejemplo el control del territorio y del acceso, además de las vías de comunicación entre norte y sur que confluían en la zona de Burriana, relacionadas con caminos que unían la costa con el interior.
Así pues, que la llanura de Burriana era un espacio idóneo para el asentamiento, especialmente desde época romana; al que siguieron los musulmanes sólo con pequeñas variaciones.

El cercano río Mijares, situado entre Burriana y Castellón, era una importante frontera, con evidencias arqueológicas a partir de la Edad del Bronce (Melchor, 2011). En época romana la citada divisoria deja de ser tal, y pasa a ser un espacio de paso; además la zona de Burriana estaba a una jornada por vía terrestre de Sagunto (la ciudad más cercana al sur), a lo que se suma una costa apta para embarcaciones de cierto 
calado, factor que no se encuentra en espacios cercanos, debido a los pantanos.

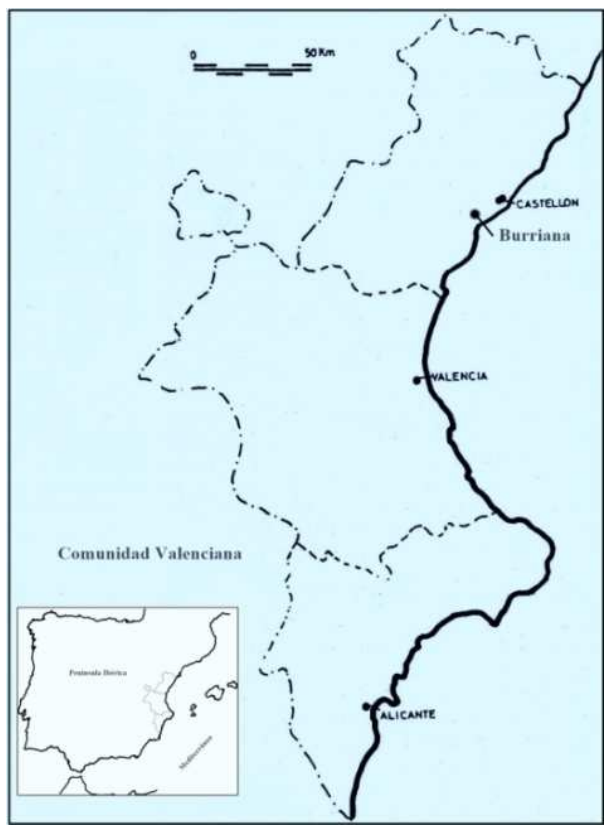

Fig. 1. Ubicación de Burriana (Plano del autor).

Desde el final de la época romana hay un retroceso demográfico y económico en la zona castellonense, y al producirse el avance islámico por la península se encontraría en situación precaria, tanto en la red de caminos como a nivel de poblamiento, a lo que unimos la ausencia de núcleos urbanos (Melchor, Benedito, 2016). Desde el emirato se recupera la explotación del territorio y la importancia del eje norte-sur, donde Tortosa y Sagunto volvían ser dos significativas ciudades unidas por la vía Augusta (Melchor, 2011). La poca información del periodo anterior al siglo XI para el territorio valenciano es un hecho señalado. Se podría suponer que las tierras que forman la provincia de Castellón se dividieron entre los centros de Tortosa y Valencia. Posteriormente, el peligro de una invasión norteafricana contribuyó a que se levantaran nuevas defensas en este territorio.

Las referencias a Medina Buryena o Buryyana y a su puerto (marsá) empiezan a final del siglo $\mathrm{X}$, describiéndola como bonita, muy habitada y con amplias tierras fértiles que llegaban hasta Sagunto (Franco, 2006), con lo cual gestionaría un amplio territorio entre las vecinas medinas de Unda (Onda) y Murbiter (Sagunto).
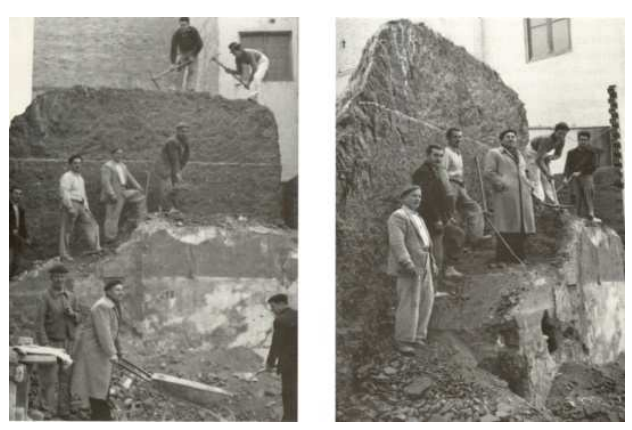

Fig. 2. Derribo de la muralla en los 50 del siglo $\mathrm{XX}$, ver Fig. 3, no 3 (Mesado, 1991).

A medida que la inestabilidad política se acerca a la zona, esta adquiere un importante papel estratégico para el acceso a la zona de La Plana, de Sagunto y más al sur, de Valencia. El hecho de que un importante enclave comercial y agrícola como Burriana deba adquirir carácter de plaza fuerte explicaría que la ocupación del territorio se conforme en un sistema de poblamiento rural costero, con alquerías y torres en el entorno de la medina, quedando los demás asentamientos menores dispersos y aislados alrededor de la vía Augusta, la principal ruta de comunicación o de huida.

La Corona de Aragón, en su conquista a principio de siglo XIII, tuvo a Burriana como punto estratégico de primer orden y objetivo primordial. Su caída arrastró al territorio hasta Sagunto y parte del norte de Castellón (al quedar su retaguardia descubierta) (Felip, 1991). La acción repobladora cristiana asegura la posesión y defensa del territorio instalando en él nuevos habitantes; esto, junto a la necesidad de premiar a colaboradores de la Corona (María, 1933) llevó a la fundación de nuevas villas mediado el siglo XIII (Nules, Vila-real y Castellón de la Plana) y a la creación de nuevos caminos, creando una especie de "anillo" alrededor de Burriana, el cual minoró definitivamente su valor estratégico y comercial, al aislarla de las principales vías de comunicación. 


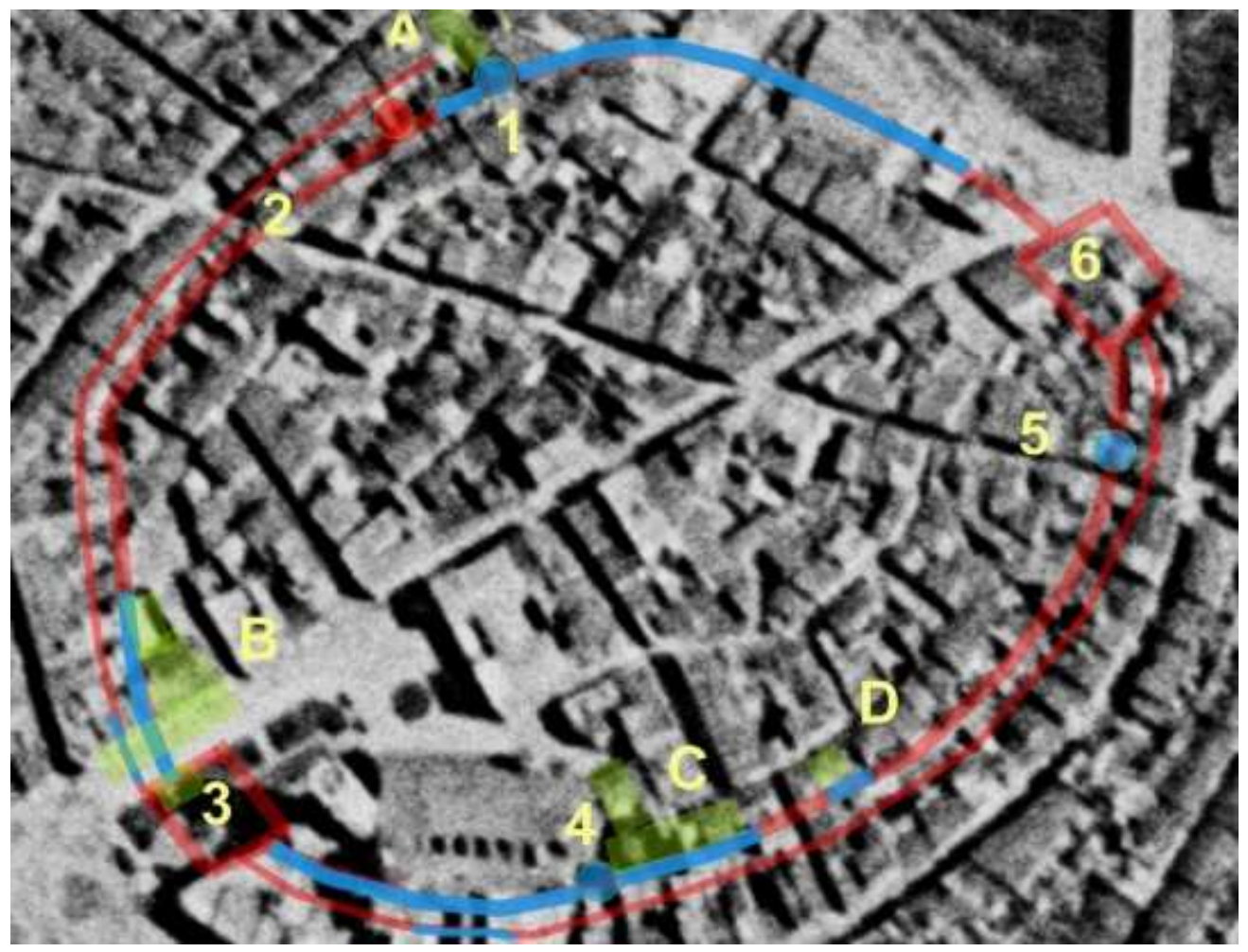

Fig. 3. Recinto amurallado (muralla y barbacana) teórico (en rojo) y sectores documentados (en azul) con el espacio para sus portales ( $\mathrm{n}^{\circ} 2,3$ y 6) y torres ( $\mathrm{n}^{\circ} 1,2,4$ y 5) y solares citados en el texto (en verde): A) C/ Sant Pascual; B) C/ Mayor; C) Casa Abadía; D) C/ San Joan (Fotografía aérea del año 1956, Instituto Cartográfico Valenciano).

\subsection{Antecedentes históricos}

La única descripción de la muralla es de Rafael Martí de Viciana (1564), que añade un ideograma con una topografía urbana idealizada (Fig. $3)$.

"Está rodeada de muro y hecha en forma circular por espacio de CCLXX braçadas por el andén del muro. Tiene quarenta torres terraplenas, dos gruesos baluartes, barbacana, fosso muy ancho y hondo, tres puertas en el muro muy fortificadas. El fosso se acostumbra de hendir de agua toda vez que quieren los del pueblo, donde se hace treynta palmos de hondoy ochenta de ancho, consérvase largos días en plenitud de una vez que le hinchan, y no tiene forma de vaziarse por sangredero, ni la tierra se puede minar, porque siendo el fosso de agua, del suelo del fosso hasta el agua manantial hay de espeso de tierra más de seys hasta ocho palmos". Además habla de "muchos travesses y reparos" en el año 1521 en la barbacana (Viciana, 1564).

Noticias posteriores comentan la destrucción paulatina de la muralla (Figs. 2 y 4), que empezó con el decreto de Nueva Planta de Felipe $\mathrm{V}^{1}$, y culminó con el derribo del portal Onda (Fig. 3, $n^{\circ}$ 2) (Roca, 1932).

\subsection{Antecedentes arqueológicos}

Se conocen intervenciones arqueológicas desde los 60 del siglo pasado, pero no es hasta la década siguiente cuando empiezan a tener cariz científico (Guichard, Mesado, 1976). Hasta el siglo XXI muy pocas fueron publicadas, y las que lo fueron arrojan conclusiones confusas, como en la c/ San Joan 16, del año 1988 (Fig. 3, letra D) donde un cimiento fue considerado un muro entre el recinto urbano y la fortificación (Verdegal, 1989). Esta identificación era equi- 
vocada, ya que se trataba del propio calicostrado de la muralla, que fue vaciada por su interior hasta la capa de bolos de su base.

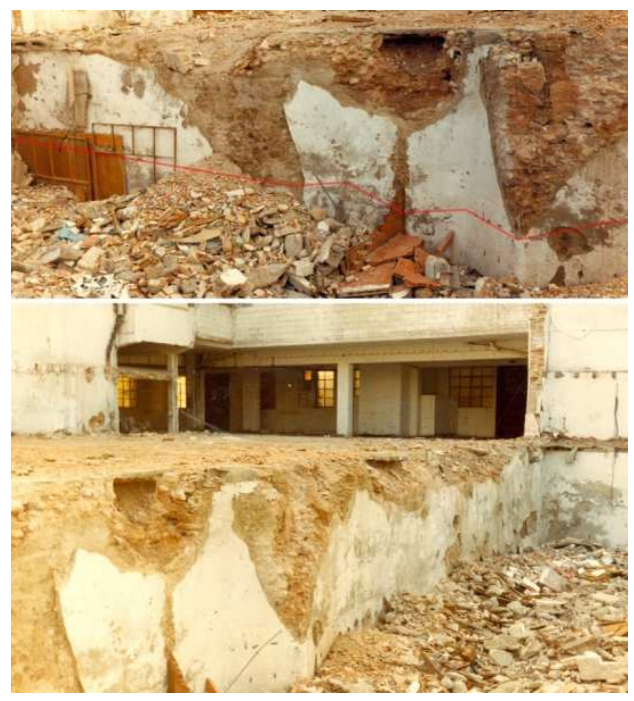

Fig. 4. Derribo de la muralla en los 80 del siglo $\mathrm{XX}$, ver Fig. $3, n^{\circ} 6$ (Fotografía del autor).

En 1967, en una zanja en la Calle Mayor (Fig. 3, letra B), N. Mesado observa la estructura defensiva medieval, describiendo de este a oeste una cimentación de mampostería de bolos, luego un espacio de tierra y la muralla de bolos, cal y tierra con un grosor de 4,4 m (en verdad es la base de una torre terraplena). Cita un espacio de tierra frente a la muralla y una cimentación de mampostería de cal y bolos, que identifica erróneamente con una de las torres del portal de Valencia (Fig. 3, no 3 ), cuando era la barbacana. Habla de un espacio limitado por una cimentación de mampostería y por el foso que correspondería a la berma (Mesado, 1991).

Durante la remodelación de la Plaza del Plá en el año 1986 (Fig. 3, no 3), se identifica la cimentación del Portal de Valencia, abierta en su lateral derecho, con entrada desde el interior de la medina (Mesado, 1991).

En la excavación realizada en el año 1995 en el patio de la casa abadía del Salvador (Fig. 3, letra C) se localizó, paralelo a 1,5 m de la muralla, un murete de tapial de $14 \mathrm{~cm}$ de grosor (sic) y 60 $\mathrm{cm}$ de altura con un suelo de mortero asociado, interpretados erróneamente como un espacio abierto y ajardinado (Ulloa, 2000), cuando en verdad eran el calicostrado y el tapial de la muralla, que fue vaciada por su interior.

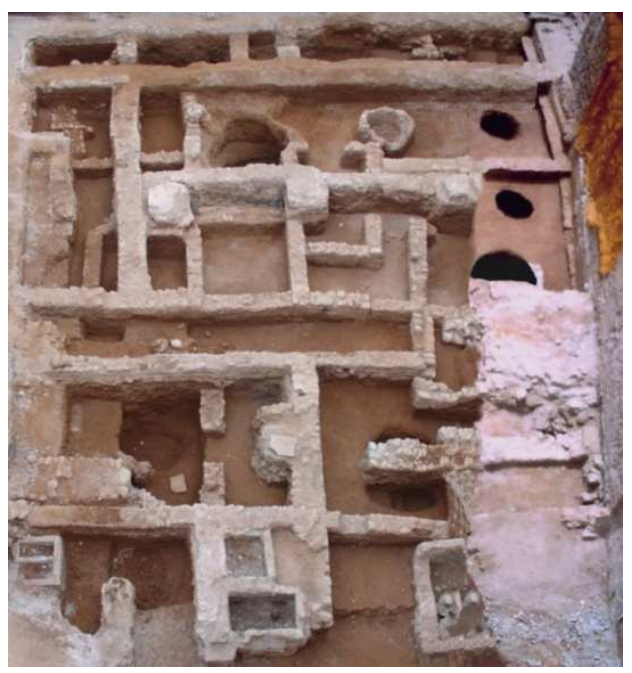

Fig. 5. Excavación Calle Mayor 26, arriba a la derecha de observan los silos excavados en el paso de ronda junto a la muralla (Fotografía del autor).

\section{Datos arqueológicos actuales}

Desde principio del siglo XXI las intervenciones arqueológicas pasan a publicarse de una forma más completa y científica. A partir de la excavación de la calle Mayor 26 esquina calle Forn de la Vila 2, realizada durante el año 2003 (Fig. 3, letra B, y Figs. 5 y 6), conocemos importantes datos sobre la ciudad hispano-musulmana. La muralla se documentó en el límite sur del solar; esta, a lo largo del siglo XIX, había sido derribada, y en su lugar se levantó un tabique de mampostería, que se apoya sobre los cimientos medievales. En esta intervención por primera vez se pudo excavar correctamente parte del alzado de la muralla, que en el sector mejor conservado alcanzaba los $150 \mathrm{~cm}$ de altura (Fig. 6). Su técnica constructiva era la tapia de tierra calicostrada, con una cimentación de grandes bolos, de mayor anchura que el lienzo defensivo, y de escasa profundidad, entre 70 y $105 \mathrm{~cm}$ (debido a construcciones posteriores fue imposible diferenciar el espesor y potencia de las tapiadas). Se conservaba parte de la disposición 
curvilínea que caracteriza la planta circular de la muralla y el callejón de tierra batida que acompaña su perímetro interior (Melchor, 2011).
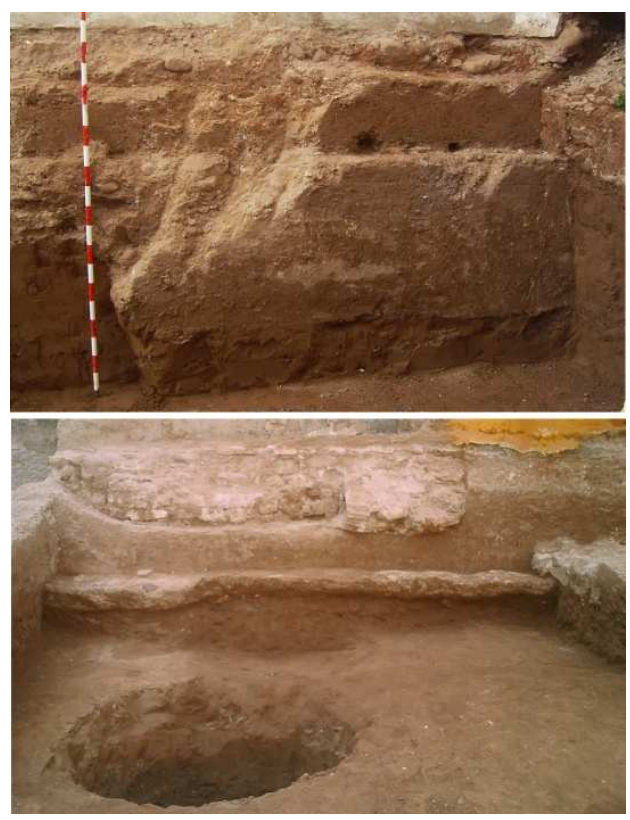

Fig. 6. Alzado y base de la muralla en la calle Mayor, 26, ver Fig. 3, letra B (Fotografía del autor).

Junto al solar estaría ubicado el Portal de Valencia, concretamente al otro lado de la actual calle Mayor (Mesado, 1991). Quedaría junto a una necrópolis hispanomusulmana (quizá un espacio abierto entre las primeras casas y la cerca defensiva) delimitada por el callejón del perímetro interior de la muralla y la antigua calle del Portal de Valencia (Melchor, 2011) (anulada en época Moderna y suplantada más al oeste por la actual Calle Mayor).

Las intervenciones del Servicio Municipal de Arqueología de Burriana entre los años 2008 y 2010 en el entorno del ábside de la iglesia del Salvador aportaron datos de interés sobre la muralla, y además sirvieron para matizar resultados de excavaciones antiguas (Verdegal, 1989; Ulloa, 2000).

Durante la intervención en el exterior del ábside de la iglesia (Fig. 3, letra C), una fase concreta se ciñó a la torre o baluarte medieval de la muralla, ubicada en el solar, sus medidas son 5 me- tros en el frente y 4,1 m en el lateral, su altura ronda los $11 \mathrm{~m}$ (Fig. 7). Esta había sido parcialmente vaciada de su tapial para la construcción de una sacristía en el siglo XVIII y la muralla de tapia real calicostrada fue derribada por parte interior hasta llegar al mortero exterior y sobre ella se construyó parte de la citada sacristía. Se documentó una cimentación bajomedieval de bolos trabados con mortero sobre el callejón perimetral, que se apoyaba en la cara interior de la muralla (Melchor, 2009a), que en ese tramo conservaba una altura aproximada de $5 \mathrm{~m}$. Durante el seguimiento de las obras, se observó que parte del lienzo defensivo se encuentra en el subsuelo del jardín y en buenas condiciones de conservación, teniendo $1,8 \mathrm{~m}$ de ancho, alcanzando una profundidad de $60 \mathrm{~cm}$ hasta al paso de ronda y su repié de 30 a $40 \mathrm{~cm}$ de altura (de bolos y mortero, como en la intervención de la calle Mayor 26, Fig. 6) y unos $70 \mathrm{~cm}$ de profundidad de cimentación, también de bolos y mortero (Melchor, 2009a). Es un dato importante que la planta baja de la torre formase un único cuerpo con la tapia de la muralla.

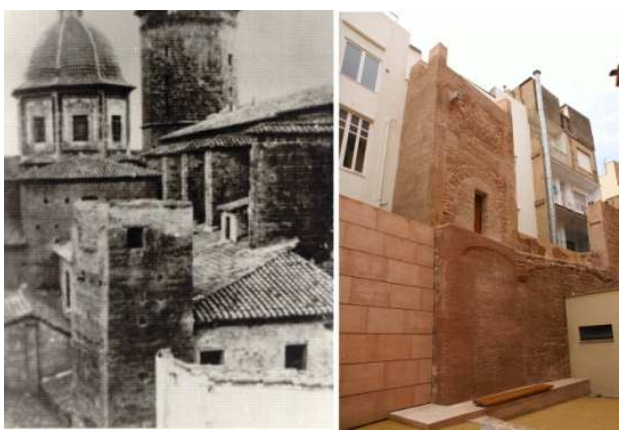

Fig. 7. Torre y la muralla junto a la iglesia del Salvador, a la izquierda a principio del siglo XX y a la derecha después de la restauración (Fig. 3, letra C) (Fotografía del Archivo Museo de Burriana).

En el solar colindante al ábside de la iglesia de El Salvador, se excavó el lugar que ocuparía la nueva casa abadía (Fig. 3, letra C). Allí la muralla había sido arrasada casi hasta sus cimientos, mediado el siglo XIX (Fig. 8). Dentro de la etapa hispanomusulmana destacamos los restos de un gran edificio al que posteriormente se le adosa un patio. En época medieval cristiana se produce una gran reforma en este espacio, con la 
construcción de dos grandes edificios adosados a la muralla. Sin duda, los hallazgos más destacados fueron el tramo de muralla y la botera de una canalización que pasa por debajo de la misma (Fig. 9) (Melchor, 2009b).

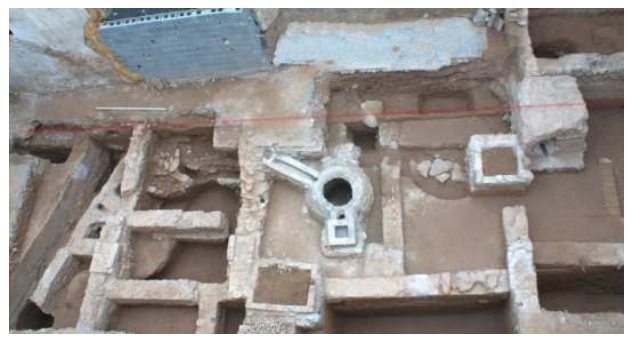

Fig. 8. Muralla en la excavación de la nueva Casa Abadía (Fotografía del autor).

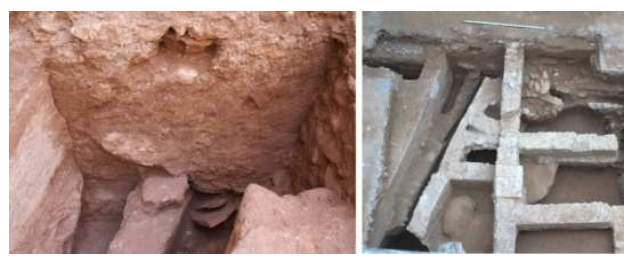

Fig. 9. Detalle e la botera de la muralla y su ubicación en el solar de la nueva casa abadía (Fotografía del Archivo Museo de Burriana).

En la Calle San Pascual 28, propiedad municipal (Fig. 3, letra A), se aprecian los restos de un tramo de la muralla y una torre terraplena (Fig. 10). Entre los años 2015 y 2019 se realizaron una serie de intervenciones que buscaron la puesta en valor de los restos medievales. Las actuaciones arqueológicas que acompañaron las obras aportaron información interesante sobre la estructura defensiva.

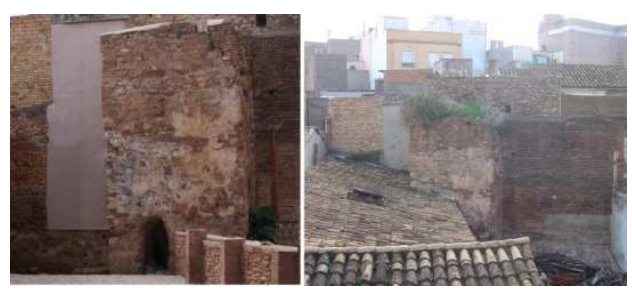

Fig. 10. Torre de la calle San Pascual después de la limpieza y en su estado inicial (Fotografía del Archivo Museo de Burriana).
En la excavación arqueológica no aparecieron restos de la barbacana. Respecto a la evolución urbanística de la muralla entre los siglos XVII y XIX, se identificó el arranque del foso en su límite más alejado del recinto defensivo, que las edificaciones posteriores hacen desaparecer paulatinamente, hasta mediado el siglo XIX. En el solar se conservan $1,5 \mathrm{~m}$ de altura de la muralla a ambos lados de la torre (Fig. 11), estando aquella recrecida con mampostería de ladrillos y piedra, reforma que pertenecería a las guerras carlistas, cuando también se reconstruiría la parte superior de la torre. En las medianeras contemporáneas del solar se ven fragmentos de la muralla y de la torre reutilizados a modo de trozos de material constructivo La torre tiene 4,1 $\mathrm{m}$ en su frente y $1,9 \mathrm{~m}$ en su lateral, siendo la altura conservada de unos 7,7 m y está compuesta por una parte superior de tapia con calicostra y el tercio inferior macizo de mampostería de piedra y mortero de cal.
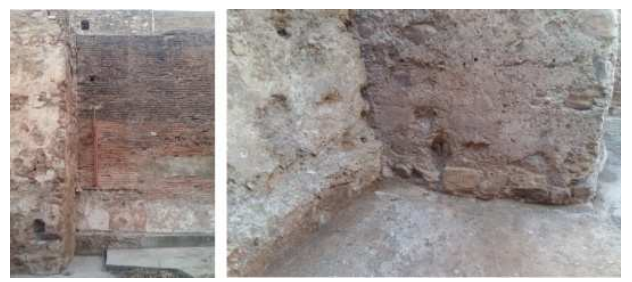

Fig. 11. Tramo de la muralla junto a la torre de la Calle San Pascual, derecha e izquierda de la misma respectivamente (Fotografía del Archivo Museo de Burriana).

La base de mampostería de otra torre con un perímetro similar a la citada arriba fue descubierta en un seguimiento arqueológico en la calle Zaragoza en el año 2019 (Fig. 3, no 5). Esta estaba arrasada hasta nivel de cimentación, encontrándose bajo el firme de la calle y las casas actuales (Figs. 12 y 13). Quizá estuviera relacionada con una puerta de la muralla que daría al camino del mar, a escasos $20 \mathrm{~m}$ al sur de la torre.

El seguimiento arqueológico de una zanja en la calle Mayor en el año 2013, frente al citado solar $n^{\circ} 26$ (Fig. 3, letra B), permitió documentar una sección completa de la estructura defensiva, compuesta por el paso de ronda interior de 4 metros de amplitud, la cimentación de la muralla 
de $1,8 \mathrm{~m}$ de ancho con otros 2,6 $\mathrm{m}$ de una torre adosada, el espacio de $6 \mathrm{~m}$ entre estas y la barbacana, la propia barbacana de 1,3 $\mathrm{m}$ de ancho y el espacio de $3 \mathrm{~m}$ hasta el pretil del foso ${ }^{2}$ (Fig. 14), desde el cual arrancaba un puente de mampostería de época Moderna, cuando se anularía el antiguo Portal de Valencia, y se abriría aquí una puerta en la muralla, alineada con la nueva calle Mayor.
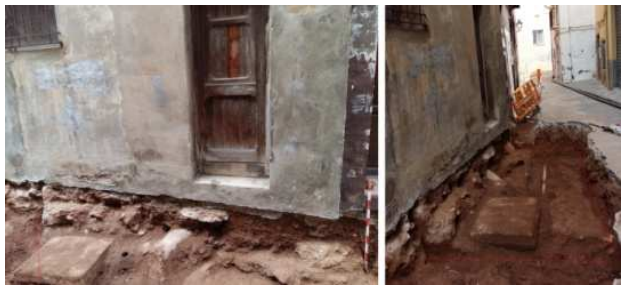

Fig. 12. Ubicación de la cimentación de la torre en la Calle Zaragoza (Fotografía del Archivo Museo de Burriana).

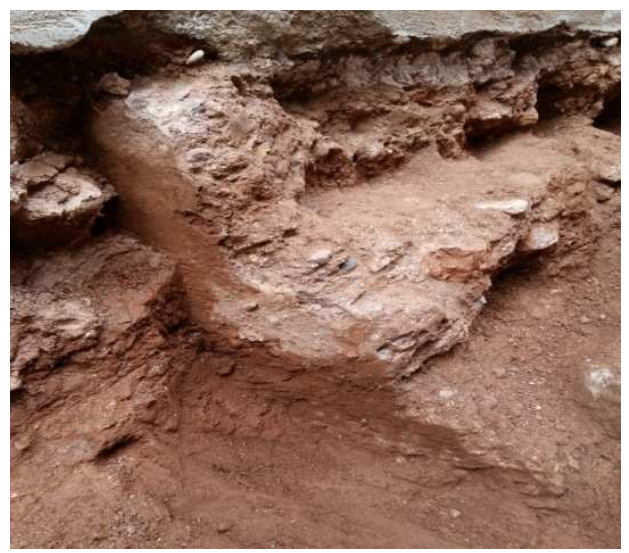

Fig. 13. Arranque de la base de la torre de la calle Zaragoza, bajo una vivienda (Fotografía del Archivo Museo de Burriana).

\section{Conclusiones}

Las recientes intervenciones arqueológicas aportaron gran cantidad de datos que han cambiado las antiguas teorías sobre el urbanismo y la muralla de la medina Buriena, mejorando el conocimiento sobre el estado de conservación y técnica constructiva de esta última, que al ser una obra de tapia real calicostrada de influencias norteafricanas, apuntaría a un momento de construcción tardío, alrededor del siglo XI, relacio- nado quizá con las incursiones cristianas y almorávides. La acompañan una barbacana y torres terraplenas que mezclan una base de mampostería maciza y tapia calicostrada (de las que se han documentado 3), junto a torres-baluarte integradas en la tapia de la muralla (como la de la iglesia del Salvador) y al menos tres portales.

Hay indicios de ocupación hispanomusulmana previa al amurallamiento, como la presencia en el tapial de la muralla de una cantidad importante de restos cerámicos, el desagüe o acequia sobre el que se construye la muralla (creando una botera y un atzucat) y la existencia de una necrópolis musulmana orientada hacia el camino de Valencia, que aparece dentro y fuera de la muralla, lo que indicaría que la construcción del lienzo defensivo dividió en dos el espacio funerario original.

Así pues, es probable que desde su fundación alrededor el siglo IX, Burriana correspondiera a una aldea (Guichard, Dómenech, 2000), cuya prosperidad se debía a su situación en un cruce de caminos, a su puerto marítimo y quizá a un cercano embarcadero fluvial ${ }^{3}$, y que se amuralla alrededor del siglo XI, ya en calidad de amal o cabeza de distrito, adquiriendo un definitivo carácter urbano.
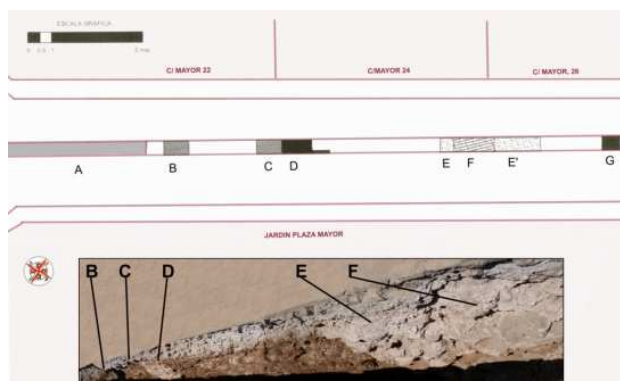

Fig. 14. Sección de la estructura defensiva aparecida en la zanja de la Calle Mayor. A) Relleno del foso; B) Pretil del foso; C y D) Barbacana; E y E') Reformas en la muralla; F) Cimentación de la muralla; G) Cimentación (Fotografía del autor).

\section{Notas}

${ }^{1}$ Hay evidencias arqueológicas e citas históricas de reconstrucciones puntuales de la muralla durante la Primera Guerra Carlista. 
${ }^{2}$ El pretil del foso, de mampostería de piedra y mortero de cal con enlucido blanco también apareció en una reciente excavación en el solar de El Plá 6 (Fig. 3, nº 5), aun inédita.
${ }^{3}$ En el siglo XIV existen noticias de la aguada de barcos y del transporte de troncos de árboles por la vía fluvial del vecino rio Mijares (Arciniega, 2011).

\section{Bibliography}

Arciniega, L. (2011). "El abastecimiento fluvial de madera al Reino de Valencia", in Montesinos, J.; Poyato, C. eds., La Cruz de los Tres Reinos. Espacio y tiempo en un territorio de frontera. Cuenca, Universidad de Castilla-LaMancha, pp. 99-134.

Felip, V. (1991). "La conquesta de Borriana al Llibre dels Fets", in Burriana en su Historia II, Ayuntamiento de Burriana Ed., Burriana, pp. 49-68.

Franco, F. (2006). "Sagunto/Murbitar en el periodo islámico. Su historia a través de los textos", in De Murbiter a Morvedre, Fundación Bancaja Ed., Valencia, pp. 47-65.

Guichartd, P.; Doménech, C. (2000). "Los orígenes de Burriana", in XXX Aniversari del Museu Arqueologic Comarcal de la Plana Baixa Burriana (1967-1997), Ayuntamiento de Burriana Ed., Burriana, pp. 125-136.

Guichard, P.; Mesado, N. (1976). Un menut poble del País Valencià durant l'època musulmana: Borriana, Ayuntamiento de Burriana Ed., Burriana, pp. 1-51.

María, R. De. (1933). El llibre del repartiment de Burriana y Villarreal, Sociedad Castellonenca de Cultura Ed., Castellón, pp. 1-312.

Melchor, J.M. (2009a). "Intervención arqueológica en el entorno del Ábside", in El Arte de Restaurar el Patrimonio. La Llum de les Imatges (Borriana, Vil-real, Castelló, 2008-2009), Generalitat Valenciana Ed., Valencia, pp. 99115.

Melchor, J.M. (2009b). "Nuevas aportaciones al conocimiento de la muralla Islámica de Burriana", in Boletín de la Asociación de Amigos de los Castillos de España. 156 a 159, Ed. Madrid, pp. 135-138.

Melchor, J.M. (2011). "La arqueología como fuente de estudio para la Burriana medieval", in La arqueología de la Buriyyana islámica a la Borriana cristiana, Ayuntamiento de Burriana Ed., Burriana, pp. 11-47.

Melchor, J.M.; Benedito, J. eds. (2016). El Palau (Burriana). Procesos de cambio cultural desde la Prehistoria hasta el siglo X, Ayuntamiento de Burriana Ed., Burriana, pp. 1-180.

Mesado, N. (1991). "La muralla y sus portales", in Burriana en su Historia II, Ayuntamiento de Burriana Ed., Burriana. pp. 69-88.

Roca, F. (1932). Historia de Burriana. Castellón de la Plana, Establecimiento tipográfico hijo de J. Armengot Ed., Castellón, pp. 1-562.

Ulloa, P. (2000). "Excavación Arqueológica en la Iglesia del Salvador de Burriana", in XXX Aniversari del Museu Arqueologic Comarcal de la Plana Baixa Burriana (1967-1997), Ayuntamiento de Burriana Ed., Burriana, pp. 205-212.

Verdegal, V. (1989). "Excavacions arqueològiques d'urgència a Borriana: la construcció defensiva medieval", in Butlletí de l'Asociació Arqueològica de Castelló Llansol de Romaní. 6-7, Ed. Castellón.

Viciana, R.M. de. (1564). Libro tercero de la Crónica de la ínclita y coronada ciudad de Valencia y de su reino, Iborra, J. ed. reimp. 2002, Universidad de Valencia Ed., Valencia, pp. 1-481. 